\title{
Xanthoangelol, a Major Chalcone Constituent of Angelica keiskei, Induces Apoptosis in Neuroblastoma and Leukemia Cells
}

\author{
Keiichi Tabata,${ }^{a}$ Kou Motani, ${ }^{a}$ Noriya Takayanagi, ${ }^{a}$ Reiko Nishimura, ${ }^{a}$ Satoru Asami, ${ }^{a}$ \\ Yumiko Kimura, ${ }^{b}$ Motohiko UkiYa, ${ }^{c}$ Daisuke Hasegawa, ${ }^{c}$ Toshihiro AKIHISA ${ }^{c}$ and \\ Takashi SUZUKI ${ }^{*, a, d}$ \\ ${ }^{a}$ Clinical Pharmacy; ${ }^{b}$ Chemical Analysis Center, College of Pharmacy, Nihon University; 7-7-1 Narashinodai, \\ Funabashi, Chiba 274-8555, Japan: ' Department of Materials and Applied Chemistry, College of Science and \\ Technology, Nihon University; 1-8 Kanda Surugadai, Chiyoda-ku, Tokyo 101-8301, Japan: and d Department of \\ Pediatrics, School of Medicine, Nihon University; 30-1 Oyaguchikami-cho, Itabashi-ku, Tokyo 173-0032, Japan. \\ Received February 28, 2005; accepted April 25, 2005
}

\begin{abstract}
Xanthoangelol, a major chalcone constituent of the stem exudates of Angelica keiskei, was evaluated for cell toxicity and apoptosis-inducing activity in human neuroblastoma (IMR-32) and leukemia (Jurkat) cells. Xanthoangelol concentration-dependently reduced the survival rates of both cell lines as revealed by the trypan blue exclusion test. Early apoptosis induced by $4 \mathrm{~h}$ incubation with xanthoangelol was detected using flow cytometry after double-staining with annexin $\mathrm{V}$ and propidium iodide (PI). Western blot analysis showed that xanthoangelol markedly reduced the level of precursor caspase- 3 and increased the level of cleaved caspase-3, but Bax and Bcl-2 proteins were not affected. These results suggest that xanthoangelol induces apoptotic cell death by activatation of caspase-3 in neuroblastoma and leukemia cells through a mechanism that does not involve Bax/Bcl-2 signal transduction. Therefore, xanthoangelol may be applicable as an effective drug for treatment of neuroblastoma and leukemia.
\end{abstract}

Key words xanthoangelol; apoptosis; neuroblastoma; leukemia

Neuroblastoma is the most common solid pediatric tumor and remarkable for its clinical heterogeneity. Despite recent advances in chemotherapy, the prognosis of advanced neuroblastoma is still very poor. However, some favorable types of neuroblastoma, especially in infants under 1 year of age, are known to regress spontaneously or mature even if widespread metastases to bone marrow, skin and/or liver (special stage: stage IVS) are present. Apoptosis is known to occur in normal development of nervous systems, and neuroblastoma is generated from neural crest cells when the apoptotic systems do not carry out. Delayed implementation of the normal apoptotic pathway has been proposed as an explanation for the spontaneous regression of favorable neuroblastoma. ${ }^{1)}$ It is reported that resistance to apoptosis plays a contributory role in the mechanism of the aggressive behavior shown by advanced neuroblastoma. ${ }^{2}$ Acute lymphocytic leukemia, like advanced neuroblastoma, is also a pediatric disease that is difficult to treat, especially in older children or those with a high amount of leukemic cells in the peripheral blood.

Angelica keiskei has been used traditionally in Japan as a diuretic, laxative, analeptic and galactagogue, and an $A$. keiskei extract was previously reported to affect metabolic activity $^{3,4)}$ and vasoconstriction ${ }^{5)}$ in rats. Moreover, A. keiskei and a major chalcone constituent of this plant, xanthoangelol, reportedly have inhibitory effects against tumor promoter activity ${ }^{6,7)}$ and metastasis. ${ }^{8)}$ Xanthoangelol possesses a chalcone structure, and some compounds related to calchones are known to have antitumor activity and to induce apoptosis. Quercetin chalcone was reported to reduce the size of implanted colon-25 tumors in vivo. ${ }^{9}$ However, there has been no report on the effects of chalcones, including xanthoangelol, on neuroblastoma.

In this study, we examined the antitumor effect and apoptosis-inducing activity of xanthoangelol against a human neuroblastoma cell line (IMR-32), and also a leukemia cell line (Jurkat) which have been widely used in previous studies of apoptosis.

\section{MATERIALS AND METHODS}

Materials Xanthoangelol $\quad\left(3^{\prime}\right.$ - $C$-geranyl-2',4,4'-trihydroxychalcone) was isolated from the stem exudate of $A$. keiskei $^{6}$ and dissolved in dimethyl sulfoxide (DMSO) (final concentration $0.2 \%$ ). IMR-32 and Jurkat were maintained in RPMI-1640 medium (Invitrogen) supplemented with $100 \mathrm{U} / \mathrm{ml}$ penicillin, $100 \mu \mathrm{g} / \mathrm{ml}$ streptomycin and $10 \%$ fetal bovine serum (FBS) (Invitrogen). The cells were maintained at $37^{\circ} \mathrm{C} / 5 \% \mathrm{CO}_{2}$ in a humid environment.

Trypan Blue Exclusion Assay The cells $\left(1 \times 10^{6}\right)$ were plated into a $60-\mathrm{mm}$ dish and maintained for $24 \mathrm{~h}$. Xanthoangelol (final concentrations $10^{-6}, 10^{-5}, 10^{-4} \mathrm{M}$ ) and vehicle were applied for $48 \mathrm{~h}$. For the IMR-32 cell protocol, the cells were stripped using $0.05 \%$ trypsin-EDTA solution after washing them in phosphate-buffered saline $(-)$. They were then washed in RPMI-1640 medium (with 10\% FBS) and counted with a phase-contrast microscope immediately after addition of an equal volume of $1 \%$ trypan blue solution. Cell viability was calculated as the ratio of surviving cells to total cells.

3-[4,5-Dimethylthiazol-2-yl]-2,5-diphenyltetrazolium Bromide (MTT) Assay IMR-32 cells $\left(1 \times 10^{4} /\right.$ well $)$ were spread onto a 96-well culture plate with phenol red-free RPMI 1640 medium (with 10\% FBS) and maintained for $24 \mathrm{~h}$. Then xanthoangelol (final concentration $10^{-8}-10^{-4} \mathrm{M}$ ) and vehicle were applied for $48 \mathrm{~h}$. After addition of $0.5 \%$ MTT solution as a $1 / 10$ volume of medium in the well, incubation was continued for a further $4 \mathrm{~h}$ at $37^{\circ} \mathrm{C} / 5 \% \mathrm{CO}_{2}$. An equal volume of stop solution $(0.04 \mathrm{~N} \mathrm{HCl}$ in isopropanol) to that of the culture medium was then added to each well and the absorbance at $570 \mathrm{~nm}$ (peak) and $630 \mathrm{~nm}$ (bottom) was 
measured after thorough pipetting to disperse the generated blue formazan.

Flow Cytometry Apoptosis was detected using a Vibrant $^{\mathrm{TM}}$ apoptosis assay kit \#3 (Molecular Probes). Cells $\left(1 \times 10^{6}\right.$ cells/dish $)$ were exposed to xanthoangelol $\left(10^{-5}\right.$ $10^{-6} \mathrm{M}$ ) or the vehicle for $4 \mathrm{~h}$. To prepare the cell sample for flow cytometry, cells were washed with annexin-binding buffer and stained with annexin V-fluorescein isothiocyanate (FITC) and propidium iodide (PI) for $15 \mathrm{~min}$. The cell samples were analyzed by a FC500 flow cytometer (Beckman Coulter) using the FL1 and FL4 range for annexin V FITC and PI, respectively.

Immunoblotting Cells were collected and lysed with the lysis buffer $(20 \mathrm{~mm}$ Tris- $\mathrm{HCl} \mathrm{pH} 8.0,137 \mathrm{~mm} \mathrm{NaCl}, 1 \%$ Nonidet P-40, 10\% glycerol, $1 \mathrm{~mm}$ phenylmethylsulfonylfluoride, protease inhibitor cocktail I (1:200; Sigma), phosphatase inhibitor cocktail II (1:100; Sigma), and $1 \mathrm{~mm}$ dithiothreitol). Protein concentration was determined using the Bradford method. ${ }^{10)}$ Cell lysates containing $20 \mu \mathrm{g}$ of total protein were loaded onto $12.5 \%$ or $15 / 25 \%$ SDS-polyacrylamide gels with Tris/glycine running buffer and transferred to polyvinylidene difluoride (PVDF) membranes (Amersham Bioscience). Each membrane was blocked with blocking buffer (5\% skim milk, $137 \mathrm{~mm} \mathrm{NaCl}$ and $20 \mathrm{~mm}$ Tris- $\mathrm{HCl}$, $\mathrm{pH}$ 7.6) for $1 \mathrm{~h}$ at room temperature and incubated with the primary antibody (anti-caspase-3 1:3000, anti-Bax (2D2) $1: 2000$ and anti-Bcl-2 (Bcl-2-100) 1:1000 (Sigma), diluted in $5 \%$ bovine serum albumin) at $4{ }^{\circ} \mathrm{C}$ overnight. After washing with Tris-buffered saline containing $0.1 \%$ Tween-20, the membrane was incubated with a secondary antibody conjugated with horseradish peroxidase (1:10000, (Sigma), diluted in 5\% skim milk) at room temperature for $1 \mathrm{~h}$. The signal was detected using an enhanced chemiluminescence Western blotting detection system (Amersham Bioscience). The density of the band was analyzed by NIH image-J software.

\section{RESULTS}

Reduction of Neuroblastoma and Leukemia Cells Survival by Xanthoangelol In the trypan blue exclusion study, $48 \mathrm{~h}$ exposure of IMR-32 and Jurkat cells to xanthoangelol markedly reduced their viability in a concentration-dependent manner (Figs. 1A, B). The highest concentration $\left(10^{-4} \mathrm{M}\right)$ of xanthoangelol showed potent cytotoxicity against both cell lines. IMR-32 cells were more sensitive than Jurkat cells to xanthoangelol at intermediate concentration. Both the MTT and trypan blue assays demonstrated concentrationdependent cytotoxicity of xanthoangelol, with an $\mathrm{EC}_{50}$ of $2.49 \times 10^{-4} \mathrm{M}$ for IMR-32 cells (Fig. 1C).

Detection of Early Apoptosis To clarify whether or not the xanthoangelol-induced cell death involved apoptosis, early apoptosis was examined using flow cytometry after annexin V and PI double staining. The distribution of stained cells is shown in Fig. 2A (control; vehicle only) and B (treated with $3 \times 10^{-5} \mathrm{M}$ xanthoangelol) in IMR-32 cells. As shown in Fig. 2C, the ratio of apoptotic IMR-32 cells was significantly increased at a xanthoangelol concentration of $3 \times 10^{-5} \mathrm{M}$, and higher concentrations induced cell death with increased cell permeability. The low survival level even in the control cells (shown in Fig. 2C) seems to be caused by

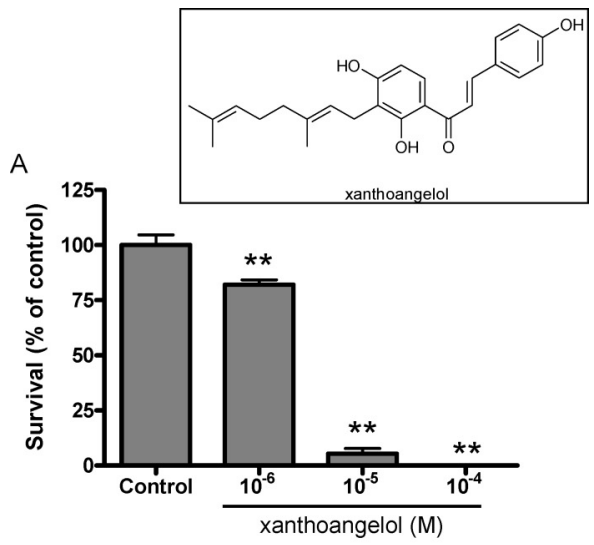

B

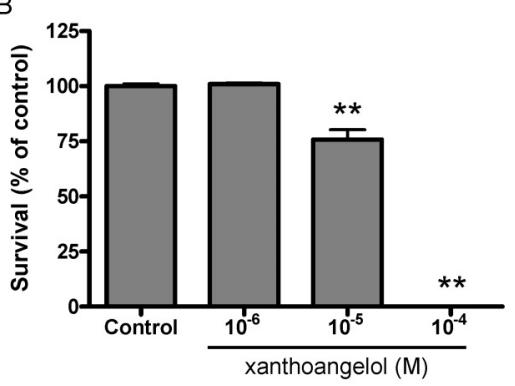

C

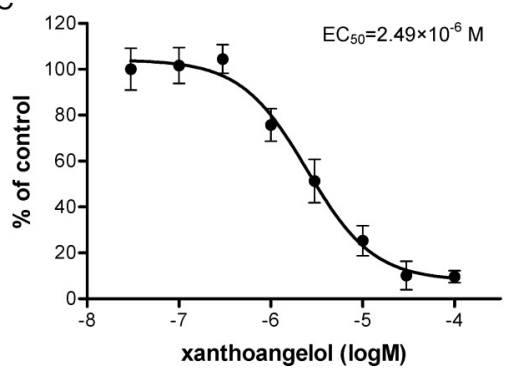

Fig. 1. Cytotoxic Effect of Xanthoangelol on IMR-32 (A) and Jurkat (B) Cells as Shown by the Trypan Blue Exclusion Test, and on IMR-32 Cells by the MTT Assay (C)

Cells were exposed to xanthoangelol for $48 \mathrm{~h}$. Each column and plot shows the mean \pm S.E.M. survival rate relative to the control group. $* * p<0.01 v s$. control compared by one-way ANOVA followed by Bonferroni's post-hoc test.

the cell membrane damage in the detaching process of adherent neuroblastoma cells from culture dishes. In Jurkat cells, xanthoangelol induced concentration-dependent early apoptosis followed by secondary cell death (Fig. 2D). In both cell lines, xanthoangelol in the concentration of $10^{-5} \mathrm{M}$, which $48 \mathrm{~h}$ exposure significantly reduced the cell viability in trypan blue assay, did not affect the parameter of apoptosis for $4 \mathrm{~h}$ application.

Activation of Caspase-3 To clarify the mechanism by which xanthoangelol induces apoptotic cell death, caspase-3 activity was evaluated by immunoblotting. In both cell lines, the bands of caspase- $3(32 \mathrm{kDa})$ were gradually diminished by xanthoangelol $\left(1 \times 10^{-4} \mathrm{M}\right)$ in a time-dependent manner. Especially in IMR-32 cells, activated caspase-3 $(19 \mathrm{kDa})$ was detected in parallel with a reduction of $32-\mathrm{kDa}$ caspase- 3 (Fig. 3). These data revealed that xanthoangelol-induced cell death occurs through activation of caspase- 3 .

Effects on Bax and Bcl-2 Expression of the proapoptotic protein Bax and the anti-apoptotic mitochondrial protein Bcl-2 was examined by immunoblotting analysis to clar- 


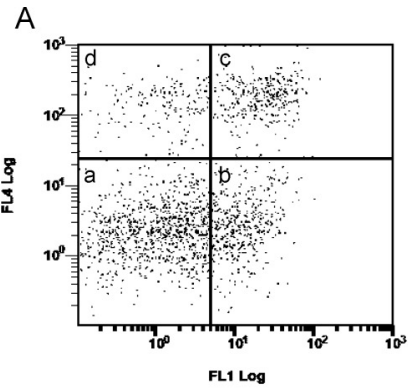

B

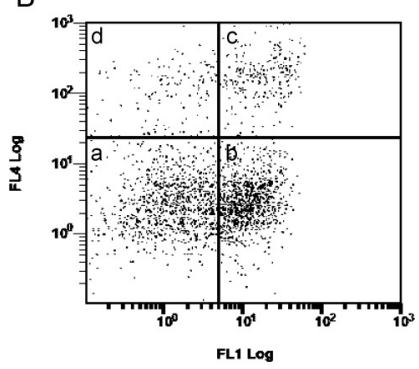

C

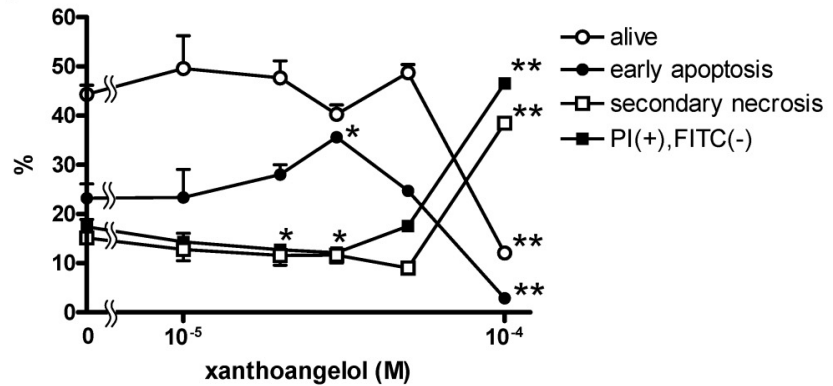

D

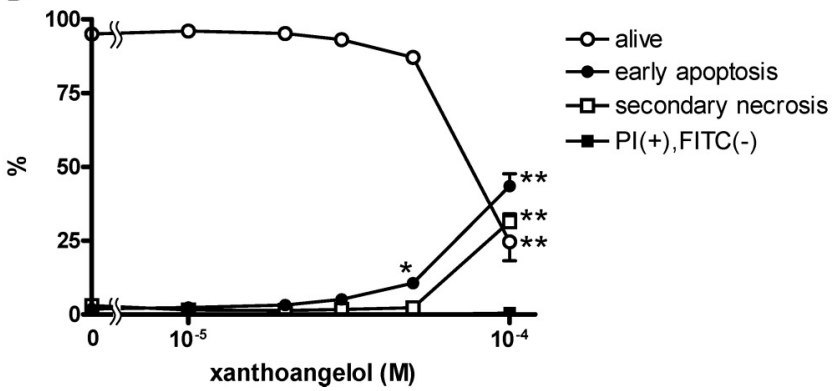

Fig. 2. Early Apoptosis and Secondary Necrosis Detected by Flow Cytometry Using Annexin V-FITC and PI Staining

Xanthoangelol $\left(10^{-6}-10^{-5} \mathrm{M}\right)$ was applied for $4 \mathrm{~h}$. The distribution of cells stained by anexin V FITC (FL1 Log) and PI (FL4 Log) in IMR-32 control cells (A) and cells treated with xanthoangelol $\left(3 \times 10^{-5} \mathrm{M}\right)(\mathrm{B})$. The letters $\mathrm{a}, \mathrm{b}, \mathrm{c}$ and $\mathrm{d}$ in the graph represent alive, early apoptosis, secondary necrosis, and cells stained by PI alone, respectively. Concentration-dependent change in the percentage of each area was shown in $C$ (IMR-32) and D (Jurkat). $* p<0.05, * * p<0.01 v s$. control compared by one-way ANOVA followed by Bonferroni's post-hoc test.

ify the partial mechanism of xanthoangelol-induced apoptosis. Xanthoangelol $\left(1 \times 10^{-4} \mathrm{M}\right)$ slightly reduced the level of Bax and increased the level of Bcl-2 in IMR-32 cells (Fig. 4A). Bax was detected in Jurkat cells, but the expression level was very low compared to IMR-32 cells (these data were obtained from same gel). And xanthoangelol had no effect on the expression of $\mathrm{Bax}$ and $\mathrm{Bcl}-2$ protein at the concentration of $1 \times 10^{-4} \mathrm{M}$ (Fig. 4B). The Bax/Bcl-2 ratio is one of the indices of the intrinsic mechanism of apoptosis in mitochondria. Xanthoangelol reduced this ratio in IMR-32 cells, it seems that xanthoangelol-induced apoptosis does not involve Bax/Bcl-2 signal transduction (Fig. 4C).

\section{DISCUSSION}

Our study investigated the cytotoxic activity of xanthoangelol, a major constituent of $A$. keiskei, which is a Japanese traditional health food, and its contribution to apoptosis in human neuroblastoma and leukemia cells.

The root of $A$. keiskei has been traditionally used as a di-
A

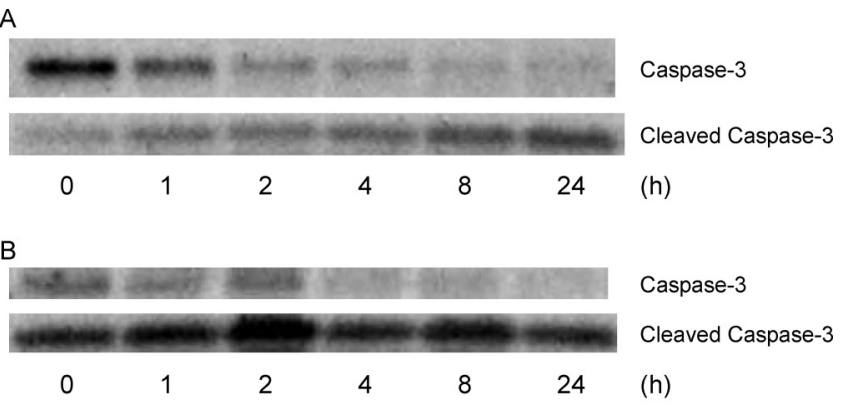

C

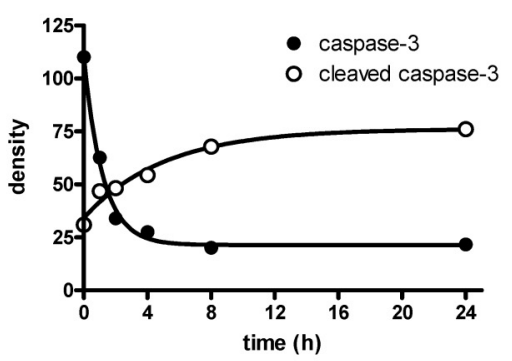

D

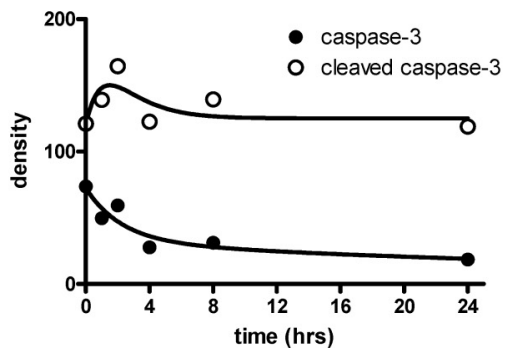

Fig. 3. Activation of Caspase- 3 by Xanthoangelol

Caspase-3 (32 kDa) and cleaved caspase-3 $(19 \mathrm{kDa})$ were detected by immunoblotting using anti-caspase-3 antibody in IMR-32 (A) and Jurkat (B) cells. Xanthoangelol $\left(1 \times 10^{-4} \mathrm{M}\right)$ was applied for $0-24 \mathrm{~h}$. The density of the bands for IMR-32 (shown in A) and Jurkat (shown in B) were analyzed and are shown in C and D respectively.

uretic, laxative, analeptic and galactagogic. Recently, scientific data on the active ingredients of $A$. keiskei have been accumulating, and some of them appear to have antitumor activity. ${ }^{6,8,11)}$ Xanthoangelol has been isolated from $A$. keiskei extract as a major effective compound, which shows antitumor-promoting activity in vitro ${ }^{6)}$ and anti-tumor growth and antimetastatic activity in vivo. ${ }^{8}$ Kimura and Baba have reported that the mechanism of this antitumor activity of xanthoangelol in Lewis lung carcinoma (LLC) cells involves inhibition of DNA synthesis within a concentration range of $10^{-5}-10^{-4} \mathrm{M}^{8)}$ In this study, the same dose of xanthoangelol induced apoptosis with caspase- 3 activation. Thus, apoptosis-inducing activity may contribute in part to the antitumor effect of xanthoangelol.

Proapoptic Bax and antiapoptic Bcl-2 are representative members of the Bcl-2 protein family. Expression of Bcl-2 is associated with an unfavorable histology of neuroblastoma. ${ }^{12}$ Up-regulation of Bax is required in order for apoptotic death to be induced in neuroblastoma cells by many drugs, such as cisplatin and ginsenoside $\mathrm{Rh} 2 .^{13,14)}$ Hence, we started the immunoblotting experiment to expect that $\mathrm{Bax} / \mathrm{Bcl}-2$ ratio was increased by xanthoangelol. But, in our study, xanthoangelol reduced the $\mathrm{Bax} / \mathrm{Bcl}-2$ ratio in IMR-32 cells, a finding that is 


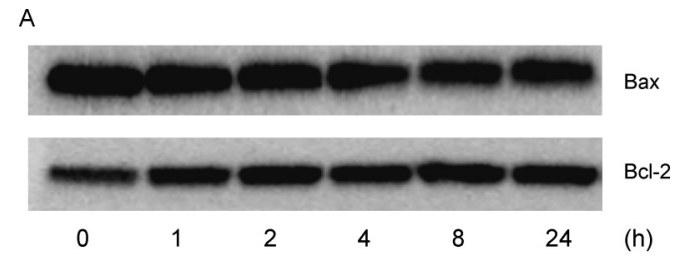

B

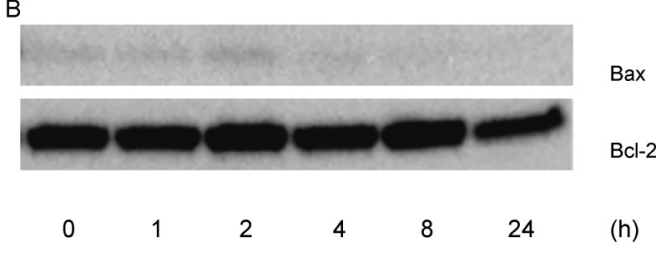

C

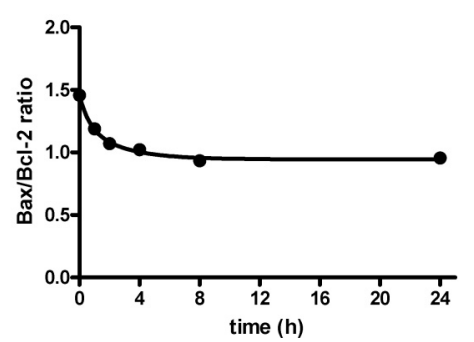

Fig. 4. Effects of Xanthoangelol on the Expression of Bax and Bcl-2 Protein

Bax and Bcl-2 were detected by immunoblotting in IMR-32 (A) and Jurkat (B) cells. Xanthoangelol $\left(1 \times 10^{-4} \mathrm{M}\right)$ was applied for $0-24 \mathrm{~h}$. The Bax/Bcl-2 ratio in IMR-32 cells is shown in $\mathrm{C}$.

in conflict with caspase-3 activation and apoptosis induction. This discrepancy seems to be caused by an effect secondary to caspase- 3 activation, such as a feedback mechanism, and xanthoangelol may therefore act downstream of Bax and Bcl2 or another pathway. Moreover, Bok and Noxa, which are also members of the Bcl-2 family, have been reported to be essential mediators of the intrinsic apoptosis pathway. ${ }^{15}$ More details of the proteins responsible need to be examined in order to clarify the apoptotic mechanism of xanthoangelol.

In the present cell survival and flow cytometry studies, IMR-32 cells were more sensitive to xanthoangelol than Jurkat cells, although the harvesting conditions differed between the two cell lines according to whether the cells were adherent or suspended. In contrast to our data, doxorubicin, a drug that is often used for neuroblastoma therapy, is reported to have lower potency against neuroblastoma cells than against Jurkat cells. ${ }^{16)}$ Moreover, the doxorubicin-induced death in IMR-32 cells is caspase-independent. ${ }^{16)}$ Neuroblastoma has the highest observed rate of spontaneous regression among human cancers. ${ }^{1)}$ As apoptosis mechanisms are involved in the chemotherapeutic sensitivity and spontaneous regression of neuroblastoma, ${ }^{12,17,18)}$ xanthoangelol as an apoptosis inducer may have comparatively high potency against neuroblastoma.

In the therapeutic protocol for advanced neuroblastoma, cyclophosphamide, doxorubicin and cisplatin are often used in combination. Although some new regimens have slightly improved the survival rate of patients with advanced neuroblastoma, the prognosis is still poor. ${ }^{19)}$ These drugs are known to induce apoptosis in some tumor cell lines, ${ }^{20-22)}$ and like them, xanthoangelol also possesses potent apoptosis-inducing activity. Moreover, unlike cisplatin, continuous administration of an effective dose of xanthoangelol has been shown not to reduce the body, liver or lung weight of mice in vivo. ${ }^{8)}$ Xanthoangelol-induced DNA synthesis inhibition was observed in LLC cells, but not in human umbilical vein endothelial cells (HUVECs) ${ }^{8}{ }^{8}$ A. keiskei has been used as a health food in Japan, and its dried yellow sap contains more than $10 \%$ xanthoangelol. Therefore, xanthoangelol has the potential to be a valuable therapeutic drug for neuroblastoma without producing adverse effects.

In summary, we have revealed that xanthoangelol induces caspase-3-dependent apoptotic cell death, which does not directly involve the Bax/Bcl-2 pathway. The apoptosis-inducing activity of xanthoangelol has not been reported previously. These results suggest that xanthoangelol may become a candidate as an antitumor agent.

Acknowledgements This work was supported by "Academic Frontier" Project for Private Universities: matching fund subsidy from MEXT (Ministry of Education, Culture, Sports, Science and Technology) 2002-2006

\section{REFERENCES}

1) Maris J. M., Matthay K. K., J. Clin. Oncol., 17, 2264-2279 (1999).

2) Poulaki V., Mitsiades N., Romero M. E., Tsokos M., Cancer Res., 61, $4864-4872$ (2001).

3) Ogawa H., Nakashima S., Baba K., Clin. Exp. Pharmacol. Physiol., 30, 284-288 (2003).

4) Park J. C., Park J. G., Kim H. J., Hur J. M., Lee J. H., Sung N. J., Chung S. K., Choi J. W., Phytother. Res., 16, S24-S27 (2002).

5) Matsuura M., Kimura Y., Nakata K., Baba K., Okuda H., Planta Med., 67, 230-235 (2001).

6) Akihisa T., Tokuda H., Ukiya M., Iizuka M., Schneider S., Ogasawara K., Mukainaka T., Iwatsuki K., Suzuki T., Nishino H., Cancer Lett., 201, 133-137 (2003).

7) Okuyama T., Takata M., Takayasu J., Hasegawa T., Tokuda H., Nishino A., Nishino H., Iwashima A., Planta Med., 57, 242-246 (1991).

8) Kimura Y., Baba K., Int. J. Cancer, 106, $429-437$ (2003).

9) Hayashi A., Gillen A. C., Lott J. R., Altern. Med. Rev., 5, 546-552 (2000).

10) Bradford M. M., Anal. Biochem., 72, 248-54 (1976).

11) Okuyama T., Takata M., Nishino H., Nishino A., Takayasu J., Iwashima A., Chem. Pharm. Bull., 38, 1084-1086 (1990).

12) Oue T., Fukuzawa M., Kusafuka T., Kohmoto Y., Imura K., Nagahara S., Okada A., J. Pediatr. Surg., 31, 251-257 (1996).

13) Park S. A., Park H. J., Lee B. I., Ahn Y. H., Kim S. U., Choi K. S., Mol. Brain Res., 93, 18-26 (2001).

14) Kim Y. S., Jin S. H., Arch. Pharm. Res., 27, 834-839 (2004).

15) Yakovlev A. G., Di Giovanni S., Wang G., Liu W., Stoica B., Faden A. I., J. Biol. Chem., 279, 28367-28374 (2004).

16) Hopkins-Donaldson S., Yan P., Bourloud K. B., Muhlethaler A., Bodmer J. L., Gross N., Oncogene 21, 6132-6137 (2002).

17) Kisenge R. R., Toyoda H., Kang J., Tanaka S., Yamamoto H., Azuma E., Komada Y., Cancer Sci., 94, 598-605 (2003).

18) van Noesel M. M., Versteeg R., Gene, 325, 1-15 (2004).

19) Iwafuchi M., Utsumi J., Tsuchida Y., Kaneko M., Matsuyama S., Ohnuma N., Taguchi N., Mugishima H., Yokoyama J., Sasaki S., Yoshioka A., Nagahara N., Fukuzawa M., Suita S., Med. Pediatr. Oncol., 27, 515-520 (1996).

20) Lee J. H., Park J. H., Yang M. H., J. Kor. Med. Sci., 12, 185-189 (1997).

21) Dole M. G., Jasty R., Cooper M. J., Thompson C. B., Nunez G., Castle V. P., Cancer Res., 55, 2576-2582 (1995).

22) Bian X., Giordano T. D., Lin H. J., Solomon G., Castle V. P., Opipari A. W., Jr., J. Biol. Chem., 279, 4663-4669 (2004). 